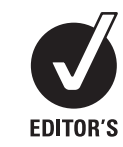

CHOICE

Department of Epidemiology and Public Health, University College London, London, UK

Correspondence to: Professor J Wardle, Health Behaviour Research Centre, Department of Epidemiology and Public Health, Gower Street, University College London, London WC1E 6BT, UK; j.wardle@ucl.ac.uk

Accepted 10 August 2009 Published Online First 30 August 2009

\title{
Weight status and perceived body size in children
}

\author{
J Saxton, C Hill, P Chadwick, J Wardle
}

\section{ABSTRACT}

Objective: To investigate associations between weight status and body size perception in children in the UK.

Design: Cross-sectional survey.

Setting: School-based sample in the UK.

Participants: 399 children (205 boys, 194 girls) aged 79 years.

Main outcome measures: Perceived body size was assessed using a visual method (Children's Body Image Scale, matching to images representing body mass indexes (BMI) from 3rd to 97th percentiles) and verbal descriptors from "too thin" to "too fat". BMI (converted to BMI SD scores using UK data) was assessed and demographic information was recorded.

Results: Modest associations between actual and perceived body size were found with visual $(r=0.43$, $p<0.001)$ and verbal $(r=0.41, p<0.001)$ methods, but there was a consistent response bias towards underestimation. Using visual matching, most children (45\%) underestimated their body size, with significantly greater underestimation $(p<0.001)$ at higher BMI. A gender-byweight group interaction ( $p=0.001$ ) showed that at lower weights girls were more accurate than boys, but at higher weights girls were less accurate. Using the verbal scale, the majority of children reported their body size as "just right" in all weight groups (52-73\%), with no sex differences.

Conclusions: Children can estimate their body size using visual or verbal methods with some accuracy, but show greater underestimation at higher weights, especially in girls. These findings suggest that underestimation is more widespread than has been assumed, which has implications for health education among school-aged children.

Women are well known to overestimate their weight and men to underestimate in many cultures. ${ }^{1-3}$ However, a trend towards greater underestimation has emerged in the past two decades, evidenced by survey comparisons from America and the UK. This could be due to changes in the normative status of overweight or effects of obesity publicity. ${ }^{4}$

Young people's perception of their weight status attracted much interest during peak concern about eating disorders, ${ }^{6}$ but is now being revisited in light of the obesity epidemic. Two studies observed the adult pattern of overestimation in young women and underestimation in young men using verbal scales, ${ }^{78}$ but a recent study with overweight adolescents showed a third underestimated their weight, with no sex differences. ${ }^{9}$ Another study using verbal and visual scales found almost half the boys and one-third of girls underestimated their size. $^{10}$

Recent research with younger children indicates a similar pattern. A Canadian study found that overweight/obese children underestimated more

\section{What is already known on this topic}

- Adults and adolescents are inaccurate in estimating their body size with more overestimation in women and more underestimation in men.

- Some evidence shows an increasing prevalence of underestimation, with women, as well as men underestimating their body size.

\section{What this study adds}

- The first study to assess body size estimation in pre-adolescents.

- Showed a high level of underestimation, particularly in overweight girls.

- Health education initiatives and weight management programmes need to be aware of the underestimation of body size.

than other weight groups, exacerbated by having overweight classmates and parents. ${ }^{11}$ Two studies of overweight/obese children reported conflicting findings: Latino children demonstrated poor body size awareness, ${ }^{12}$ whereas an Italian sample showed good accuracy. ${ }^{13}$ However, both studies assessed body perception using sketched silhouettes representing increasing weights but not specific body mass indexes (BMI) so judgements of absolute accuracy were not possible.

Body images with known sizes are now available. ${ }^{14} 15$ These complement verbal description methods (eg, scales from "very underweight" to "very overweight"), 571516 which cannot discriminate between body size being misperceived or only mislabelled. These methods have not yet been used with pre-adolescents.

The present study investigated body size perception in pre-adolescents using verbal descriptor and BMI-calibrated visual-matching methods to examine associations between perceived and actual body size across the weight spectrum in a communitybased British sample.

\section{METHODS}

\section{Participants}

Children were recruited into the Physical Exercise and Appetite in CHildren Study (PEACHES), a longitudinal study of weight gain during childhood in five north London schools (UK) that includes parent and child measures of eating behaviour and physical activity. Families with children in years 3/ 4 (7-9 years old; $\mathrm{n}=531$ ) were invited to 
participate. 405 parents (76\%) provided informed consent for body image and anthropometric measurements. One child had insufficient English to complete the questions; four were unavailable on the testing day. Complete data were collected from 399 children (205 boys, 194 girls) between September 2006 and February 2007. Ethical approval for the study was granted by the University College London Committee on the Ethics of Non-NHS Human Research.

\section{Measures \\ Demographics}

Date of birth, gender, ethnicity and home postcodes of children were provided by schools. Ethnicity was reported as white, black/mixed black, Asian/mixed Asian or other, but re-coded to white/non-white because of limited sample sizes. Postcodes were used to estimate socioeconomic deprivation of home neighbourhoods according to 1991 census information using the Townsend index. ${ }^{17}$ Scores above zero indicate above national average levels of deprivation. Missing postcodes were replaced by the mean value for the child's school.

\section{Anthropometry}

Measurements were taken by trained researchers using standard protocols. Height without shoes was recorded to the nearest millimetre using Leicester height measures (Seca, Birmingham, UK). Weight was measured using Tanita TBF300MA, to the nearest tenth of a kilogramme minus $1 \mathrm{~kg}$ for clothing.

BMI from height and weight was converted into age and sexappropriate BMI standard deviation scores (SDS) using British 1990 reference data. ${ }^{18}$ Weight categories were created using International Obesity Taskforce criteria for healthy weight, overweight and obesity, recently adapted to include underweight (thinness grade 1, 2 or 3). ${ }^{19}$ We created a subdivision of the healthy weight group into lower $(<50$ th centile but not underweight) and higher healthy weight ( $>50$ th centile but not overweight) groups to examine responses across the adiposity spectrum.

\section{Children's body image scale}

The children's body image scale (CBIS $)^{14}$ consists of seven gender-specific figures posed in the anatomical position (figure 1). Each figure is a modified photograph of an anonymised, pre-pubescent boy or girl with a BMI within the specified range for one of seven National Center for Health Statistics (NCHS) percentiles (3rd-97th) for 10 year olds. ${ }^{20}$ Figures are horizontally arranged in ascending order of adiposity and labelled ' $A$ ' to ' $G$ ' (alphabetical labels were converted into numbers ' 1 ' to ' 7 ', respectively, for analysis). "Perceived body size" is assessed by asking the child to identify the figure most similar in size to them. Mean (SD) figures selected by girls and boys aged 7-12 years in the validation sample were 3.10 (1.32) and 2.91 (1.27), respectively. ${ }^{14}$ Good test-retest reliability for perceived body size (girls $r=0.85$, boys $r=0.76, p<0.001$ ) has been demonstrated. ${ }^{15}$

Because CBIS figures denote gender and age-specific BMI ranges, each child's BMI, unadjusted for age/gender, was used to determine the figure closest to their size ("actual body size"). The accuracy of perceived size was calculated by subtracting the "actual" figure number from the "perceived" (score range -6 to +6 ). Negative scores indicate underestimation, zero accurate selection and positive scores overestimation of size.

We also administered a verbal descriptor scale for perceived body size, with one item: "do you think your body is: much too thin, too thin, just right, too fat, or much too fat", used in previous studies. ${ }^{16} 2122$ "Much too fat" and "too fat" categories were combined, as were "much too thin" and "too thin", because few children selected the extremes.

\section{Procedure}

Children were tested individually at school in a private space. The child was guided through the CBIS and asked to identify the figure most similar to their own body size. The verbal scale and response options were then read aloud by the researcher from a laminate visible to the child, who pointed to or verbalised their answer. It was emphasised that there were no right or wrong answers, and that the researchers would not share the child's responses, although the child was free to do so if they wanted. Finally, anthropometric measurements were taken. Children were not given feedback about measurements in accordance with ethical requirements.

\section{Data treatment and statistical analyses}

Although the body image measures produce ordinal data, they were treated as interval in line with previous research using the $\mathrm{CBIS}^{14}{ }^{15}$ and other widely used verbal and visual body image scales $^{111623}$ to enable comparability of findings. We used Pearson's correlations to assess associations between perceived and actual body size for the visual measure, and between BMI SDS and verbal ratings. Data were also analysed separately by sex because boys may be less accurate than girls at this age. ${ }^{14}$ Differences between correlations for boys and girls were tested for statistical significance $\left(Z_{o b s}\right){ }^{24}$ The accuracy of visually perceived body size was plotted by sex-weight groups. We compared proportions of children underestimating or overestimating their size in each weight group $\left(\chi^{2}\right)$ and used analyses of covariance (ANCOVA) to investigate weight group differences in perceived body size accuracy. The data did not violate ANCOVA assumptions.

\section{RESULTS}

\section{Sample characteristics}

Descriptive statistics overall and by sex are presented in table 1. There were similar numbers of boys and girls (51\% male). Most children were in lower or higher healthy weight groups $(65 \%)$, $16 \%$ were classified as underweight and $19 \%$ as overweight/ obese. Compared with UK averages, this sample had fewer overweight/obese and more underweight children. ${ }^{25}$ The sample was ethnically mixed (52\% non-white) and neighbourhood socioeconomic deprivation was high (4.31).

Table 2 shows the percentage of children whose actual body size matched each figure and those choosing each figure as like them.

\section{Perceived body size: visual matching}

Actual and perceived body size were correlated $(r=0.43$, $p<0.001)$ indicating that fatter children tended to choose fatter figures and vice versa. Correlations were significantly stronger in girls $(r=0.49, p<0.001)$ than boys $(r=0.32, p<0.001$; $\left.\mathrm{Z}_{\mathrm{obs}}=-2.02\right)$.

In the whole sample children showed considerable underestimation (table 3). A quarter of children had BMI in the higher range (CBIS figures $5-7$, table 2 ), but only $10 \%$ selected those figures as a match. ANCOVA including weight group, ethnicity, gender and Townsend score showed a significant main effect of weight group $(\mathrm{F}(4,360)=59.43, \mathrm{p}<0.001)$ and a significant gender-by-weight interaction $(\mathrm{F}(4,360)=5.05, \mathrm{p}=0.001)$ with 
Table 1 Anthropometric and demographic sample characteristics: (mean (SD) or percentage)

\begin{tabular}{|c|c|c|c|}
\hline & $\begin{array}{l}\text { Girls } \\
\text { (n = 194) }\end{array}$ & $\begin{array}{l}\text { Boys } \\
\text { (n = 205) }\end{array}$ & $\begin{array}{l}\text { Total sample } \\
(\mathrm{n}=399)\end{array}$ \\
\hline Age, years, months & $8.28(0.62)$ & $8.27(0.65)$ & $8.28(0.64)$ \\
\hline $\mathrm{BMI}, \mathrm{kg} / \mathrm{m}^{2}$ & $16.57(2.73)$ & $16.47(2.54)$ & $16.52(2.63)$ \\
\hline BMI, SD* & $0.12(1.40)$ & $0.12(1.31)$ & $0.12(1.35)$ \\
\hline BMI, centile & $52.68(34.93)$ & $51.38(34.40)$ & $52.01(34.62)$ \\
\hline \multicolumn{4}{|l|}{ Weight category $\dagger$} \\
\hline$\%$ Underweight & $14.9(\mathrm{n}=29)$ & $17.1(\mathrm{n}=35)$ & $16(n=64)$ \\
\hline$\% \leqslant 50$ th Centile but not underweight & $30.4(n=59)$ & $31.7(n=65)$ & $31.1(n=124)$ \\
\hline$\%>50$ th Centile but not overweight & $35.6(n=69)$ & $33.2(n=68)$ & $34.3(\mathrm{n}=137)$ \\
\hline \% Overweight & $12.9(\mathrm{n}=25)$ & $13.7(\mathrm{n}=28)$ & $13.3(n=53)$ \\
\hline$\%$ Obese & $6.2(n=12)$ & $4.4(n=9)$ & $5.3(n=21)$ \\
\hline \multicolumn{4}{|l|}{ Ethnicity } \\
\hline$\%$ White & $42.8(n=83)$ & $43.9(n=90)$ & $43.4(n=173)$ \\
\hline$\%$ Non-white & $52.1(n=101)$ & $52.2(n=107)$ & $52.1(n=208)$ \\
\hline \% Ethnicity missing & $5.2(n=10)$ & $3.9(\mathrm{n}=8)$ & $4.5(n=18)$ \\
\hline Area deprivation level: & $4.33(3.46)$ & 4.28 (3.54) & $4.31(3.50)$ \\
\hline
\end{tabular}

no other significant effects. A clear pattern from overestimation to underestimation from lighter to heavier ends of the weight spectrum was confirmed by the linear trend $(p<0.001)$.

Mean scores on perceived body size accuracy by sex/weight groups are shown in figure 2 indicating the degree of body size "misperception" (the mean number of figures away from actual body figure) and the direction of error (over or underestimation). It shows that healthy weight girls overestimated or underestimated less than boys, whereas obese girls underestimated more than boys.

\section{Perceived body size: verbal ratings}

Verbal ratings (scored 1-5) and BMI SDS were significantly correlated $(r=0.41, p<0.001)$. In contrast to the visual method there were no differences between girls $(r=0.41)$ and boys $\left(r=0.44 ; Z_{o b s}=0.36\right)$. The majority of children in all weight groups identified their body size as "just right" (table 4) including $58 \%$ and $52 \%$ of overweight and obese children indicating underestimation of size. Many healthy weight children also reported being "too thin" (20\% of lower and $8 \%$ of higher healthy weight), again suggesting underestimation of size.

\section{Comparing visual and verbal methods}

Correlations between perceived body size and BMI SDS were comparable for visual $(r=0.41, p<0.001)$ and verbal $(\mathrm{r}=0.42, \mathrm{p}<0.001)$ ratings. Visual and verbal ratings correlated significantly with one another $(r=0.35, p<0.001)$, but

Table 2 Proportions of children matched to each of the seven CBIS figures according to measured BMI and the children's own perceptions

\begin{tabular}{lll}
\hline $\begin{array}{l}\text { CBIS figure category } \\
\text { number }\end{array}$ & $\begin{array}{l}\text { \% of children (n) in each } \\
\text { figure category based on } \\
\text { measured BMI (actual body } \\
\text { size) }\end{array}$ & $\begin{array}{l}\text { \% of children (n) who chose } \\
\text { each figure as most like } \\
\text { theirs (perceived body size) }\end{array}$ \\
\hline 1 & $19.0(76)$ & $12.3(49)$ \\
2 & $19.3(77)$ & $24.3(97)$ \\
3 & $21.3(85)$ & $35.8(143)$ \\
4 & $15.8(63)$ & $18.3(73)$ \\
5 & $18.0(72)$ & $7.8(31)$ \\
6 & $5.5(22)$ & $1.3(5)$ \\
7 & $1.0(4)$ & $0.3(1)$ \\
\hline
\end{tabular}

BMI, body mass index; CBIS, children's body image scale. ${ }^{14}$ the absolute degree of overestimation varied by method. Among overweight/obese children, $57 \%$ underestimated using verbal ratings compared with $92 \%$ using the visual method.

\section{DISCUSSION}

To our knowledge this is the first study to investigate the accuracy of body size perception in pre-adolescent children across the weight spectrum using a BMI-calibrated visual scale, and is unusual in comparing visual and verbal estimation methods. BMI SDS was modestly correlated with both indicators of perceived size, suggesting general awareness of body size in boys and girls. However, consistent biases were observed, with the verbal method revealing a strong preference for "just right", and the visual that more than one-third of children selected a figure slimmer than their own.

The accuracy of body size perception using visual matching varied with weight status. Lighter children $(<50$ th centile of healthy weight) were more likely to identify a figure larger than their own, but heavier children showed a striking tendency towards underestimation of size, particularly obese girls. Over $90 \%$ of overweight/obese children chose a figure substantially smaller than their own. The verbal descriptor method confirmed the underestimation seen with the visual method, with fewer than half of overweight/obese children identifying themselves as "too fat". Using the verbal scale, $58 \%$ of overweight children and $52 \%$ of obese children selected "just right".

One explanation for the results with the verbal scale is that children were reluctant to admit to "thinness" or "fatness", especially given the phrasing "too thin/fat". This could also be explained by the fewer response options available with the verbal scale (5) compared with the visual (7), although few children chose the extreme figures on the visual scale. Girls may be more reluctant than boys to use these terms of themselves. Both thin and fat images are described more negatively than mid-range figures by children around this age, ${ }^{26}{ }^{27}$ and children may choose not to self-identify with stigmatised body sizes. However, using the visual task, the most frequently chosen figures represented the 25 th and 10 th centiles, both of which are relatively thin, suggesting a genuine underestimation of size, whether the judgement is absolute or relative. The visual-matching task can be considered a more precise measure of body size perception, which could explain the greater sensitivity to sex differences. 
Table 3 Percentage $(\mathrm{n})$ of children underestimating, accurately identifying and overestimating their body size using visual ratings

\begin{tabular}{lccc}
\hline & $\begin{array}{l}\%(\mathbf{n}) \text { Choosing a } \\
\text { thinner figure } \\
\text { (underestimation) }\end{array}$ & $\begin{array}{l}\% \text { (n) Choosing the } \\
\text { correct figure } \\
\text { (accurate) }\end{array}$ & $\begin{array}{l}\text { \% (n) Choosing a } \\
\text { fatter figure } \\
\text { (overestimation) }\end{array}$ \\
\hline Underweight $(\mathrm{n}=64)$ & $3.1(2)$ & $29.7(19)$ & $67.2(43)$ \\
Boys & $0.0(0)$ & $28.6(10)$ & $71.4(25)$ \\
Girls & $6.9(2)$ & $31.0(9)$ & $62.1(18)$ \\
50th Centile but not underweight $(\mathrm{n}=124)$ & $22.6(28)$ & $31.5(39)$ & $46.0(57)$ \\
Boys & $23.1(15)$ & $24.6(16)$ & $52.3(34)$ \\
Girls & $22.0(13)$ & $39.0(23)$ & $39.0(23)$ \\
$>$ 50th Centile but not overweight $(\mathrm{n}=137)$ & $59.1(81)$ & $25.5(35)$ & $15.3(21)$ \\
Boys & $72.1(49)$ & $19.1(13)$ & $8.8(6)$ \\
Girls & $46.4(32)$ & $31.9(22)$ & $21.7(15)$ \\
Overweight $(\mathrm{n}=53)$ & $90.6(48)$ & $9.4(5)$ & $0.0(0)$ \\
Boys & $89.3(25)$ & $10.7(3)$ & $0.0(0)$ \\
Girls & $92.0(23)$ & $8.0(2)$ & $0.0(0)$ \\
Obese $(\mathrm{n}=21)$ & $95.2(20)$ & $4.8(1)$ & $0.0(0)$ \\
Boys & $88.9(8)$ & $11.1(1)$ & $0.0(0)$ \\
Girls & $100(12)$ & $0.0(0)$ & $0.0(0)$
\end{tabular}

*Based on International Obesity Taskforce Criteria with additional subdivision of lower and higher healthy weight groups. ${ }^{19}$

The predominance of underestimation rather than overestimation, especially in girls, is surprising given the widespread assumption that most girls "feel fat", regardless of their true size; a "fact" regularly reiterated by the media. The change towards underestimation observed in this and other recent studies could be due to changes in societal norms, whereby conceptions of "just right" are based on perceptions of the "average", and as the population average is considerably larger than before, higher body weights would become normalised. This has been suggested as a mechanism for inaccurate weight status perception in adults, ${ }^{4}$ but it would not explain the widespread choice of relatively thin CBIS figures.

In the context of related research, our results are similar to findings with adolescents and adults indicating widespread underestimation of body size, which is more pronounced in overweight/obese individuals. ${ }^{1-3} 7$ The main difference is that adult men seem to be more prone to underestimation than women, whereas in children we found either no sex difference (verbal method) or greater underestimation in heavier girls (visual method). Whether this is an effect of maturation or a cohort effect remains unclear.

Figure 1 Mean inaccuracy (standard error) of body size perception using visual ratings.
These results raise the question of whether underestimation matters. Perhaps young children should feel "just right", and the fewer who feel body dissatisfaction the better. But there must also be concern about longer-term consequences if children cannot perceive themselves accurately. One reason for low public awareness of overweight may be that perceptions are clouded by extreme media images of obesity, which perpetuate dissociation between the "just right" self and obese "others".

Body size misperception could influence the perceived relevance of health recommendations and the efficacy of weight management interventions. ${ }^{11}$ In children of this age, parents are the main gatekeepers of lifestyle change, and they also underestimate their children's weights. ${ }^{28}$ Children's own perceptions ought to be considered if weight management practices are to be taken forward into later childhood. Whereas young children do not consider their weight and associated management in the same way as older children or adults, the inclusion of sensitive weight feedback has been shown to be beneficial to weight management in a similar age group ${ }^{29}$ and could be adapted for specialist health education. Understanding of the magnitude of body size misperception using the CBIS could be a useful
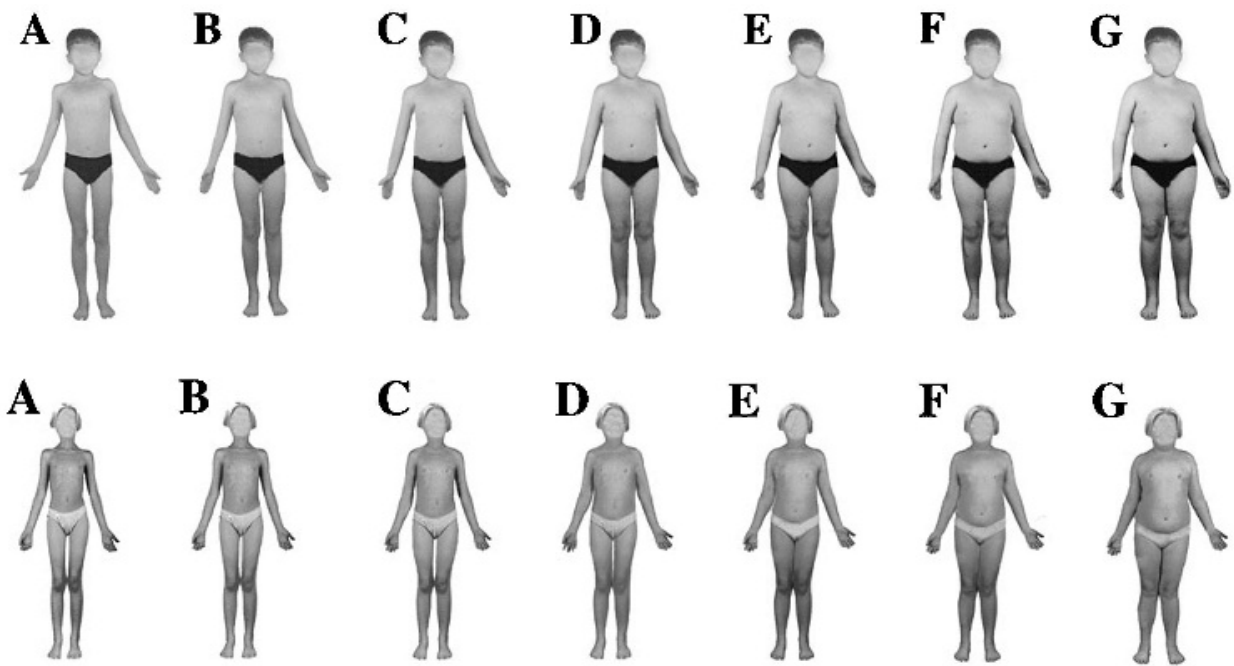
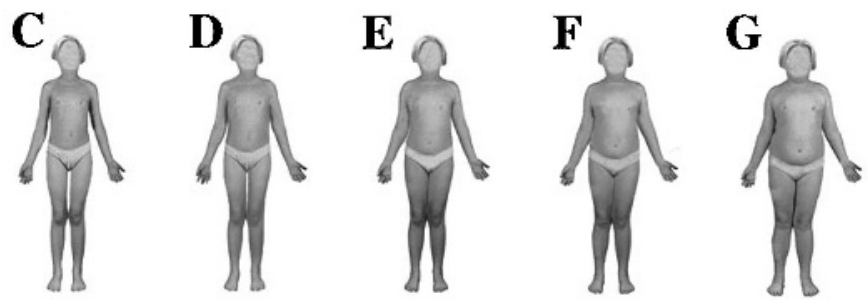
Table 4 Percentage $(n)$ of children identifying their body size as too thin, just right or too fat using verbal ratings

\begin{tabular}{|c|c|c|c|}
\hline Weight category* & $\begin{array}{l}\% \text { (n) Reporting body is } \\
\text { "too thin" or "much too } \\
\text { thin" }\end{array}$ & $\begin{array}{l}\% \text { (n) Reporting } \\
\text { body is "just right" }\end{array}$ & $\begin{array}{l}\% \text { (n) Reporting body } \\
\text { is "too fat" or "much } \\
\text { too fat" }\end{array}$ \\
\hline Underweight $(n=64)$ & $34.4(22)$ & $60.9(39)$ & $4.7(3)$ \\
\hline Boys & $34.3(12)$ & $62.9(22)$ & $2.9(1)$ \\
\hline Girls & $34.5(10)$ & $58.6(17)$ & $6.9(2)$ \\
\hline$\leqslant 50$ th Centile but not underweight $(n=124)$ & $16.9(21)$ & $72.6(90)$ & $10.5(13)$ \\
\hline Boys & $23.1(15)$ & $64.6(42)$ & $12.3(8)$ \\
\hline Girls & $10.2(6)$ & $81.4(48)$ & $8.5(5)$ \\
\hline$>50^{\text {th }}$ Centile but not overweight $(n=137)$ & $8.0(11)$ & $70.8(97)$ & $21.2(29)$ \\
\hline Boys & $4.4(3)$ & $75.0(51)$ & $20.6(14)$ \\
\hline Girls & $11.6(8)$ & $66.7(46)$ & $21.7(15)$ \\
\hline Overweight $(\mathrm{n}=53)$ & $0.0(0)$ & $58.5(31)$ & $41.5(22)$ \\
\hline Boys & $0.0(0)$ & $53.6(15)$ & $46.4(13)$ \\
\hline Girls & $0.0(0)$ & $64.0(16)$ & $36.0(9)$ \\
\hline Obese $(n=21)$ & $0.0(0)$ & $52.4(11)$ & $47.6(10)$ \\
\hline Boys & $0.0(0)$ & $55.6(5)$ & $44.4(4)$ \\
\hline Girls & $0.0(0)$ & $50.0(6)$ & $50.0(6)$ \\
\hline
\end{tabular}

${ }^{*}$ Based on International Obesity Taskforce Criteria with additional subdivision of lower and higher healthy weight groups. ${ }^{19}$

adjunct to delivering the most appropriate and individualised feedback strategy.

There are several limitations to acknowledge. Ethnic differences were not explored because a larger sample with more overweight/obese children would be required. Second, although there was a good parental response, we could not determine whether children of non-responders differed significantly on characteristics measured in the study. Parents of heavier children may have selected themselves out of the study, but school-wide data were not available to confirm this. The study also reports cross-sectional findings, although the children will be followed up annually for 3 years allowing comparisons of children who underestimate body size at baseline with those who are aware of their size.

\section{CONCLUSION}

These results indicate that children can estimate their body size with visual-matching and verbal-rating methods, but the degree of precision is moderated by weight status, with underweight children overestimating and heavier children, especially girls, underestimating body size. Findings from the verbal scale showed a tendency for children of all sizes to perceive themselves as "just right". With the visual task it was clear that most children, especially in the heavier groups, saw themselves as thinner than they were.

Acknowledgements: The authors gratefully acknowledge the ongoing contribution of the parents, children and schools in the study

Funding: PEACHES is supported by Cancer Research UK (grant code C1418/A6124). The study sponsor had no role in the study design; in the collection, analysis and interpretation of data; in the writing of the report; or in the decision to submit the paper for publication.

Competing interests: None.

Ethics approval: Ethical approval for the study was granted by the University College London Committee on the Ethics of Non-NHS Human Research.

Patient consent: Obtained.

Provenance and peer review: Not commissioned; externally peer reviewed.
Figure 2 Mean inaccuracy (standard error) of body size perception using visual ratings.

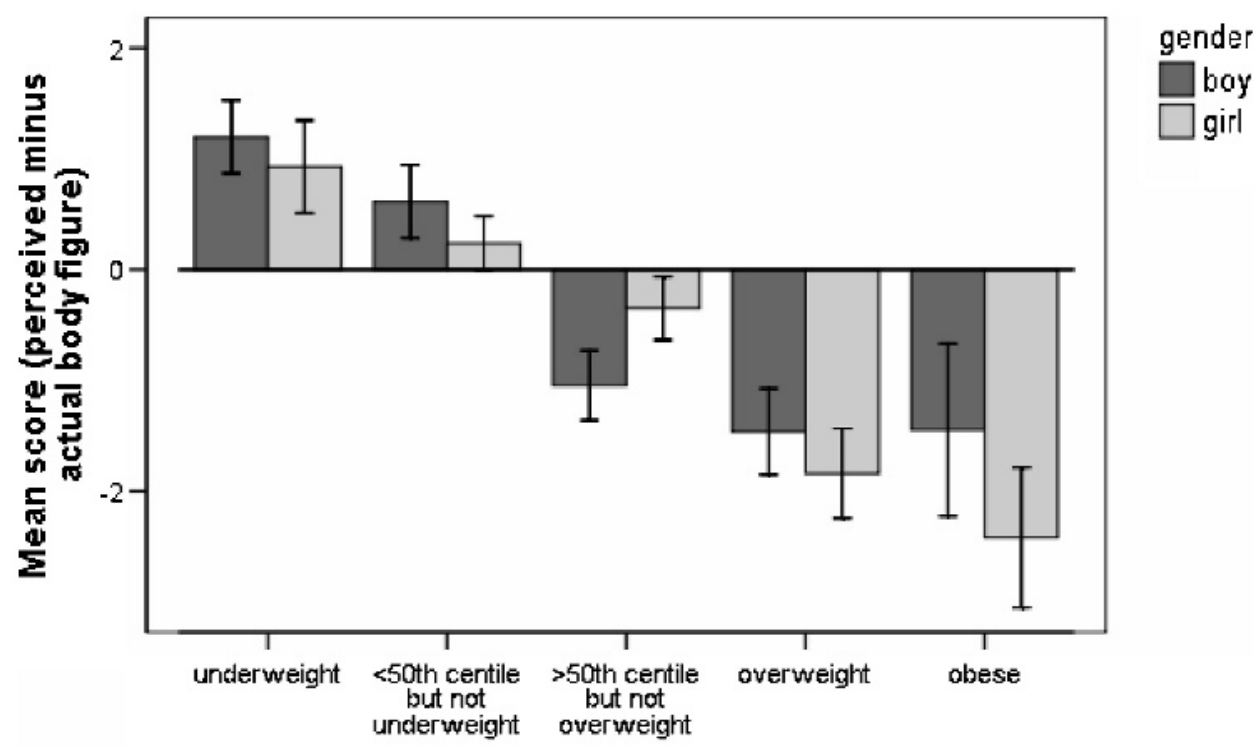

Weight Group 


\section{REFERENCES}

1. Inoue M, Toyokawa S, Miyoshi Y, et al. Degree of agreement between weight perception and body mass index of Japanese workers: MY health up study. J Occup Health 2007;:49:376-81

2. Wardle J, Griffith J. Socioeconomic status and weight control practices in British adults. J Epidemiol Commun Health 2001:55:185-90.

3. Emslie C, Hunt K, Macintyre S. Perceptions of body image among working men and women. J Epidemiol Commun Health 2001;55:406-7.

4. Johnson-Taylor WL, Fisher RA, Hubbard VS, et al. The change in weight perception of weight status among the overweight: comparison of NHANES III (1988-1994) and 1999-2004 NHANES. Int J Behav Natr Phys Activity 2008:5:9.

5. Johnson F, Cooke L, Croker $\mathrm{H}$, et al. Changing perceptions of weight in the UK: comparison of two population surveys. BMJ 2008;337:a494.

6. Farrell C, Lee M, Shafran R. Assessment of body size estimation: a review. Eur Eat Disord Rev 2005; 13:75-88.

7. Brener ND, Eaton DK, Lowry $\mathrm{R}$, et al. The association between weight perception and BMI among high school students. Obes Res 2004;12:1866-74.

8. Xie B, Chih-Ping C, Spruijt-Metz D, et al. Weight perception and weight-related sociocultural and behavioral factors in Chinese adolescents. Prev Med 2006;42:229_ 34.

9. Edwards N, Pettingell S, Borowsky I. Where perception meets reality: selfperception of weight and weight-related behaviours in a nationally representative sample of overweight adolescents. Pediatrics 2009; in press.

10. Chaimovitz R, Issenman R, Moffat T, et al. Body perception: do parents, their children, and their children's physicians perceive body image differently? J Pediatr Gastroenterol Nutr 2008;47:76-80.

11. Maximova K, McGrath JJ, Barnett T, et al. Do you see what I see? Weight status misperception and exposure to obesity among children and adolescents. Int $\mathrm{J}$ Obes 2008;32:1008-15.

12. Intagliata V, Ip EH, Gesell SB, et al. Accuracy of self- and parental perception of overweight among Latino preadolescents. N C Med J 2008;69:88-91.

13. Gualdi-Russo E, Albertini A, Argani L, et al. Weight status and body image perception in Italian children. J Hum Nutr Diet 2008;21:39-45.

14. Truby H, Paxton SJ. Development of the Children's Body Image Scale. Br J Clin Psychol 2002; 41:185-203
15. Truby H, Paxton SJ. The Children's Body Image Scale: reliability and use with international standards for body mass index. Br J Clin Psychol 2008;47:119-24.

16. Wardle J, Marsland L. Adolescent concerns about weight and eating; a socialdevelopment perspective. J Psychosom Res 1990;34:377-91.

17. Townsend $\mathbf{P}$, Phillimore $\mathbf{P}$, Beattie $A$. Health and deprivation: inequality and the North. London: Croom Helm, 1988.

18. Cole TJ, Freeman JV, Preece MA. Body-mass index reference curves for the UK, 1990. Arch Dis Child 1995:73:25-9.

19. Cole TJ, Flegal KM, Nicholls D, et al. Body mass index cut offs to define thinness in children and adolescents: international survey. BMJ 2007;335:194.

20. Hamill PV, Drizd TA, Johnson CL, et al. Physical growth: National Center for Health Statistics percentiles. Am J Clin Nutr 1979;32:607-29.

21. Sands ER, Wardle J. Internalization of ideal body shapes in 9-12-year-old girls. Int J Eat Disord 2003;33:193-204.

22. Wardle J, Watters R. Sociocultural influences on attitudes to weight and eating: results of a natural experiment. Int J Eat Disord 2004;35:589-96.

23. Collins ME. Body figure perceptions and preferences among preadolescent children. Int J Eat Disord 1991:10:199-208.

24. Edwards AL. Statistical methods, 2nd edn New York. Holt, Rinehart and Winston Inc, 1967.

25. NHS. Health Survey for England 2006: CVD and risk factors adults, obesity and risk factors children. 31 January 2008. www.ic.nhs.uk/pubs/HSE06CVDandriskfactors (accessed August 2007).

26. Wardle J, Volz C, Golding C. Social variation in attitudes to obesity in children. Int J Obes 1995:19:562-9.

27. Margulies AS, Floyd RG, Hojnoski RL. Body size stigmatization: an examination of attitudes of African American preschool-age children attending Head Start. J Pediat Psychol 2008;33:487-96.

28. Miller JC, Grant AM, Drummond BF, et al. DXA measurements confirm that parental perceptions of elevated adiposity in young children are poor. Obesity 2007;15:16571.

29. Bibeau WS, Moore JB, Caudill P, et al. Case study of a transtheoretical case management approach to addressing childhood obesity. J Pediatr Nurs 2008;23:92100

Provenance and peer review: Commissioned; not externally peer reviewed.

Arch Dis Child 2009:94:949. doi:10.1136/adc.2009.172171 